\title{
ACEITAÇÃO SENSORIAL DE LEITE INTEGRAL ULTRA HIGH TEMPERATURE E ATITUDES DOS CONSUMIDORES EM RELAÇÃO ÀS EMBALAGENS DE DIFERENTES MARCAS DO PRODUTO
}

\author{
Acceptance sensory of milk Ultra High Temperature \\ and consumer attitudes of packaging of different \\ brands of the product
}

\begin{abstract}
Marlice Salete Bonacina ${ }^{l *}$, Luana Zamboni ${ }^{1}$, Leonardo Souza da Rosa ${ }^{l}$
\end{abstract}
\begin{abstract}
RESUMO
O estudo teve como objetivo avaliar a aceitação sensorial de diferentes marcas de leite UHT integral, bem como identificar e quantificar a importância de atributos da embalagem e rotulagem do leite na atitude de compra dos consumidores. Foram coletadas seis marcas diferentes de leite UHT integral, as quais foram submetidas ao teste de aceitação, utilizando uma escala hedônica híbrida de $9 \mathrm{~cm}$. Os dados foram submetidos à análise de variância, utilizando o Software Estatística 6.0. A embalagem e a rotulagem das diferentes marcas de leite foram utilizadas para aplicação da técnica de grupo de foco. A partir dos resultados, foi possível verificar que não ocorreu diferença $(p>0,05)$ entre as marcas de leite UHT em relação a aceitação sensorial. Foi possível verificar ainda, a influência da frequência de consumo do leite na aceitação do produto, caracterizado por três nichos de consumidores. A partir das sessões de grupo de foco observou-se que $61,1 \%$ dos participantes observam as embalagens e os rótulos do leite no momento da compra, já 38,9\% argumentaram que são consumidores fiéis a determinada marca. No que se refere a existência de selos de certificação de qualidade, verificou-se que $72,2 \%$ dos participantes não observam a existência destas certificações no momento da compra do leite. Além disso, 77,8\% não mudaram seus hábitos de consumo em relação a marca do leite, mesmo após constatação de fraude. Conclui-se, que a frequência de consumo do
\end{abstract}

1 Instituto Federal de Educação Ciência e Tecnologia do Rio grande do Sul (IFRS), Rua Domingos Zanella, 104, Bairro Três Vendas, 99713-028, Erechim, RS, Brasil.E-mail: marlice.bonacina@erechim. ifrs.edu.br

* Autor para correspondência.

Recebido / Received: 03/09/2015

Aprovado / Approved: 01/03/2016 
leite, influencia na sua aceitação sensorial, e, alguns consumidores, desconhecem os riscos que as adulterações realizadas no leite podem ocasionar para a sua saúde.

Palavras-chave: consumidor; qualidade; fraude, grupo de foco.

\begin{abstract}
The study aimed to evaluate the sensory acceptance of different brands of whole UHT milk; identify and quantify the importance of attributes of the packaging and labeling of milk in the purchase attitude of consumers excure six different brands of whole UHT milk were collect, which were submitted to the acceptance test, using a hybrid hedonic scale of $9 \mathrm{~cm}$. The data were submitted to ANOVA using the Statistical Software 6.0. The packaging and labeling of different brands of milk, were used for application of the focus group technique. From the results, we found that there was no difference $(\mathrm{p}>0.05)$ between the brands of UHT milk, in relation to sensory acceptance. It was also possible to verify the influence frequency of the milk consumption of acceptance of the product, characterized by three clusters of consumers. From the focus group sessions it was found that $61.1 \%$ of participants observe the packaging and labeling milk at the time of purchase. However, $38.9 \%$ argued that they are faithful consumers excure to a determined brand. As regards the existence of quality certification seals, it was found that $72.2 \%$ of participants do not observe the existence of these certifications when buying milk. In addition, $77.8 \%$ have not changed their spending habits in relation to milk brand. It is concluded that the milk consumption frequency, influence on sensorial acceptance, and some consumers are unaware of the risk that the tamper carried out in milk can cause to their health.
\end{abstract}

Keywords: consumer; quality; fraud; focus group.

\section{INTRODUÇÃO}

Nos últimos anos, o mercado de leite no Brasil vem passando por um período de expansão e um dos produtos que mais cresceu em produção foi o chamado leite longa vida, oriundo da ultra pasteurização através do processo Ultra High Temperature (UHT), cuja produção nacional representa $75 \%$ do total de leite fluído consumido no país (ABVL, 2014).

Neste processo, o leite é homogeneizado e submetido, durante 2 a 4 segundos, a uma temperatura entre $130{ }^{\circ} \mathrm{C}$ e $150^{\circ} \mathrm{C}$, mediante um processo térmico de fluxo contínuo, sendo imediatamente resfriado a uma temperatura de $32{ }^{\circ} \mathrm{C}$ e envasado em condições assépticas em embalagens estéreis e hermeticamente fechadas, visando a obtenção de um produto bacteriologicamente estéril e que minimize as alterações nas características nutricionais e sensoriais do leite cru e refrigerado que lhe deu origem (BRASIL, 2011; TRONCO, 2013).

A eficiência do processo UHT depende da sua temperatura de estocagem e do método de tratamento térmico utilizado. O leite ultra pasteurizado pelo processo de aquecimento direto (injeção direta de vapor no leite) tornase instável e forma um gel quando estocado por algumas semanas em temperatura ambiente, sendo que permanece estável por um longo tempo quando estocado em temperatura de refrigeração. A homogeneização do leite após o tratamento térmico poderá ser responsável por um leve aumento da viscosidade, devido à quebra dos glóbulos de gordura e formação de subunidades com maior capacidade 
de hidratação, podendo apresentar volumes maiores que os originais (VIDAL-MARTINS et al., 2005).

Desta forma, fatores como aspectos de produção, aspectos tecnológicos e qualidade da matéria-prima podem influenciar as características sensoriais do leite UHT, principalmente no que se refere ao atributo sabor. Neste sentido, o regulamento Técnico de Identidade e Qualidade do Leite UHT, estabelece que o produto obtido deve apresentar sabor característico, ausência do gosto amargo ou ácido, ocorrendo a predominância de um leve sabor a "cozido", decorrente da decomposição da lactose em virtude do tratamento térmico (McSWEENEY; FOX, 2009; BRASIL, 2011).

O estado do Rio Grande do Sul encontra-se entre os maiores produtores de leite no Brasil, entretanto, nos últimos três anos, a baixa qualidade do leite cru e refrigerado destinado ao processamento UHT vem sendo motivo de questionamentos por parte dos consumidores brasileiros. A insegurança acontece devido a duas grandes operações em nível nacional deflagradas pelos órgãos regulamentadores, as quais resultaram na comprovação de adulterações e fraudes, além da retirada das prateleiras de seis marcas de leite UHT comercializadas no Rio Grande do Sul. Nestas operações foi identificada a presença de substâncias como água oxigenada e hidróxido de sódio (Operação Ouro Branco) e ureia e formol (Operação Leite Compensado), ocasionando a ocorrência de defeitos como geleificação, sedimentação, desenvolvimento de sabores e odores desagradáveis, os quais exercem grande influência sobre a aceitação do produto pelo consumidor (NÖRNBERG et al., 2009; ZENI et al., 2013; OZER; AKDEMIR-EVRENDILEK, 2014).

$\mathrm{Na}$ indústria de lácteos, a avaliação das características sensoriais do leite UHT, na forma como elas são percebidas pelos consumidores, é um componente essencial no desenvolvimento, manutenção, otimização, melhoria da qualidade e avaliação do seu potencial de mercado (DRAKE, et al., 2006; YATES; DRAKE, 2006).

Dentre as diversas metodologias utilizadas pela análise sensorial, encontram-se os testes afetivos quantitativos, cujo propósito principal, é a avaliação da preferência, dos atributos sensoriais dos consumidores com relação a produtos e de sua aceitação, a qual pode ser influenciada por outros fatores importantes como hábitos alimentares, aspectos culturais e socioeconômicos, experiências anteriores ao alimento, preço, marca, embalagem e informações do rótulo, os quais estão relacionados com a expectativa que o indivíduo possui em relação ao produto (STONE; SIDEL, 2004; MEILGAARD et al., 2007; CHAE et al., 2010; GOMES et al., 2012).

Segundo Della Lucia; Minim (2006), os atributos da embalagem podem levar o consumidor a comprar o produto, enquanto os atributos sensoriais confirmam a aceitação e podem determinar a sua recompra. Neste contexto, o uso de técnicas de pesquisa qualitativa para o estudo da percepção do produto pelo consumidor e de sua decisão de compra, tem sido bastante difundido. Um dos métodos de pesquisa, que pode ser utilizado para se obter as opiniões e atitudes dos consumidores em relação às embalagens e rótulos de produtos, é a técnica de grupo de foco. Esta técnica consiste em uma discussão interativa, em que o moderador foca a atenção do grupo em um conjunto de tópicos pré-determinados, para discutir opiniões e pontos de vista. Pode ser utilizado para identificar as características relevantes de determinado produto, que interferem na escolha dos consumidores, ou ainda, discutir conceitos de novos produtos e levantar atributos importantes de embalagens (KLEEF et al., 2005).

Neste contexto, este estudo teve como objetivo avaliar a aceitação sensorial de diferentes marcas de leite UHT integral, bem como identificar e quantificar a importância 
de atributos da embalagem e rotulagem do leite na atitude de compra dos consumidores através da técnica grupo de foco.

\section{MATERIAL E MÉTODOS}

\section{Aceitação sensorial do leite UHT}

No mês de agosto de 2014, foram coletadas aleatoriamente em estabelecimentos comerciais localizados na cidade de Erechim - RS, seis amostras de leite UHT integral, correspondentes a seis diferentes marcas. As amostras foram transportadas ao Laboratório de Análises Sensorial do Instituto Federal de Educação, Ciência e Tecnologia do Rio Grande do Sul campus Erechim. A coleta das amostras foi realizada considerando-se como critério de seleção a integridade física, hermeticidade e conformação das embalagens.

No laboratório, as diferentes marcas de leite, foram submetidas ao teste de aceitação, realizado por 52 consumidores. O número de consumidores foi definido, conforme recomendação de Stone; Sidel (1993) e o número de amostras de leite de acordo com Queiroz; Treptow (2006). Estes autores salientam que o número de amostras a serem avaliadas por sessão depende de vários fatores. No entanto, em média, quatro a seis amostras são recomendadas por prova.

Os consumidores foram predominantemente do sexo feminino (67\%) e com idade entre 18 e 56 anos. Antes de realizar o teste sensorial, os julgadores assinaram o Termo de Consentimento de Participação na análise sensorial e responderam um questionário contendo questões sobre dados pessoais (idade, sexo, escolaridade) e o consumo do leite.

As amostras foram servidas a temperatura de $7^{\circ} \mathrm{C}$, sendo a ordem de apresentação monódica e balanceada, em copos plásticos descartáveis e codificados, utilizando uma escala hedônica híbrida de nove (9) pontos, ancorada na região central e nos extremos, com anotações verbais, sendo desgostei mui- tíssimo a esquerda, gostei muitíssimo a direita e nem gostei/nem desgostei ao centro (VILLANUEVA et al., 2005).

Durante a avaliação sensorial, foi solicitado aos julgadores enxaguar a boca com água e fazer uma pausa entre as degustações, para minimizar o efeito da fadiga sensorial (DELLA LUCIA; MINIM, 2006). Os dados foram submetidos à Análise de Variância, utilizando o Software Estatística 6.0.

\section{Sessões de Grupos de Foco}

Três sessões de grupos de foco foram realizadas no mês de outubro de 2014, com um total de 18 consumidores, recrutados por terem o hábito de consumir leite UHT, no mínimo, quatro vezes na semana.

As sessões de grupos de foco foram conduzidas por um único moderador em uma sala com capacidade para acomodar os participantes confortavelmente. Os consumidores sentaram-se em torno de uma mesa redonda para permitir a interação, o contato visual e a harmonia da discussão. Cada sessão durou, aproximadamente, 75 minutos.

No início de cada sessão, o moderador apresentou o propósito da técnica e o objetivo do estudo. Aos participantes foi assegurado que não existiam respostas certas ou erradas para as questões abordadas e foram encorajados a expressar suas opiniões, mesmo que estas fossem divergentes das respostas dos demais membros do grupo.

Iniciou-se a discussão com perguntas a respeito da opinião dos consumidores e suas atitudes em relação às embalagens e rótulos de leite UHT. Em seguida, embalagens rotuladas de seis marcas comerciais foram apresentadas, separadamente e cada apresentação foi seguida por um roteiro de perguntas previamente elaborado (Quadro 1). Para cada sessão utilizou-se uma ordem diferente de apresentação das embalagens, sendo esta aleatória. 
As sessões de grupos de foco foram anotadas e gravadas por um assistente. A partir das anotações e gravações, foram obtidas as respostas dos 18 participantes, a respeito das embalagens e rótulos de leite UHT. As sessões dos grupos de foco foram planejadas e realizadas de acordo com as etapas descritas por Della Lucia; Minim (2006).

\section{RESULTADOS E DISCUSSÃO}

\section{Aceitação sensorial do leite UHT}

Os resultados referentes ao teste de aceitação das diferentes marcas de leite integral UHT estão descritos na Tabela 1, onde é possível verificar que não ocorreu diferença significativa $(p>0,05)$ entre as seis marcas de leite UHT. Este resultado corrobora com os obtidos por Gomes et al., (2012), os quais não verificaram diferença significativa quando avaliaram a aceitação sensorial de diferentes marcas de leite UHT integral, em que os consumidores também desconheciam as marcas de leite que estavam avaliando.

A partir das respostas fornecidas pelos consumidores foi possível observar que aproximadamente $29 \%$ dos avaliadores que realizaram o teste não consomem leite UHT integral ou consomem apenas duas vezes ao mês (Figura 1), ficando assim pouco familiarizados com o produto.

Você observa as embalagens e os rótulos dos leites que consome?

O que você observa?

O que mais chama a sua atenção?

O que você achou desta embalagem e deste rótulo?

Você gostaria de ver alguma outra informação no rótulo?

Quais são as características positivas que esta embalagem e o rótulo apresentam?

Quais são as características negativas que esta embalagem e o rótulo apresentam?

Informações nutricionais e de ingredientes influenciam sua decisão de compra do leite?

No momento de realizar a compra do leite UHT, você considera a existência de certificações no rótulo da embalagem? Quais certificações você considera?

Você poderia identificar algumas marcas de leite UHT que apresentaram problemas de qualidade, durante a Operação Leite Compensado.

Quadro 1 - Roteiro de perguntas para as sessões de grupo de foco

Tabela 1 - Valores médios do teste de aceitação das seis marcas de leite integral UHT

\begin{tabular}{|c|c|c|c|c|c|c|}
\hline \multirow{2}{*}{ Atributo Sensorial } & \multicolumn{6}{|c|}{ Marcas* } \\
\hline & A & B & $\mathrm{C}$ & $\mathrm{D}$ & $\mathrm{E}$ & $\mathrm{F}$ \\
\hline Aceitação cor & $6,0^{\mathrm{a}}$ & $5,6^{\mathrm{a}}$ & $6,3^{\mathrm{a}}$ & $6,4^{\mathrm{a}}$ & $5,9^{a}$ & $6,0^{\mathrm{a}}$ \\
\hline Aceitação sabor & $6,0^{\mathrm{a}}$ & $5,6^{\mathrm{a}}$ & $5,9^{\mathrm{a}}$ & $5,2^{\mathrm{a}}$ & $5,7^{\mathrm{a}}$ & $5,8^{\mathrm{a}}$ \\
\hline Aceitação global & $5,8^{\mathrm{a}}$ & $5,5^{\mathrm{a}}$ & $5,8^{\mathrm{a}}$ & $5,3^{\mathrm{a}}$ & $5,8^{\mathrm{a}}$ & $6,0^{\mathrm{a}}$ \\
\hline
\end{tabular}

*Médias com letras iguais, na mesma linha, não diferem significativamente entre si $(\mathrm{p}>0,05)$. 
A influência da frequência do consumo na aceitabilidade do produto, pode ser melhor observada, quando avaliado as respostas dos consumidores de forma agrupada, onde é possível verificar três nichos de consumidores (Figura 2).

No primeiro nicho verificou-se que $60 \%$ dos avaliadores consomem o leite sete vezes na semana; no segundo, esse consumo ocorre por $22 \%$ e no terceiro por apenas $6 \%$. Analisando a aceitação global do leite nestes nichos, foi possível observar valores médios de 4,$6 ; 6,0$ e 7,2, respectivamente, mostrando que a maior frequência de consumo é associada a um maior grau de exigência em relação a qualidade sensorial.

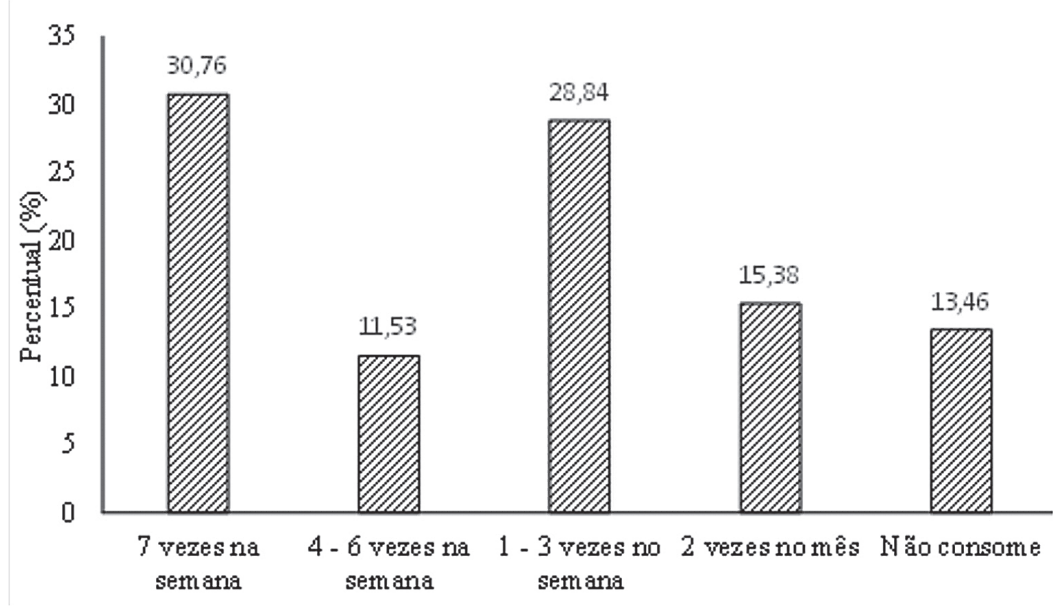

Figura 1 - Frequência de consumo do leite UHT dos participantes do teste de aceitação

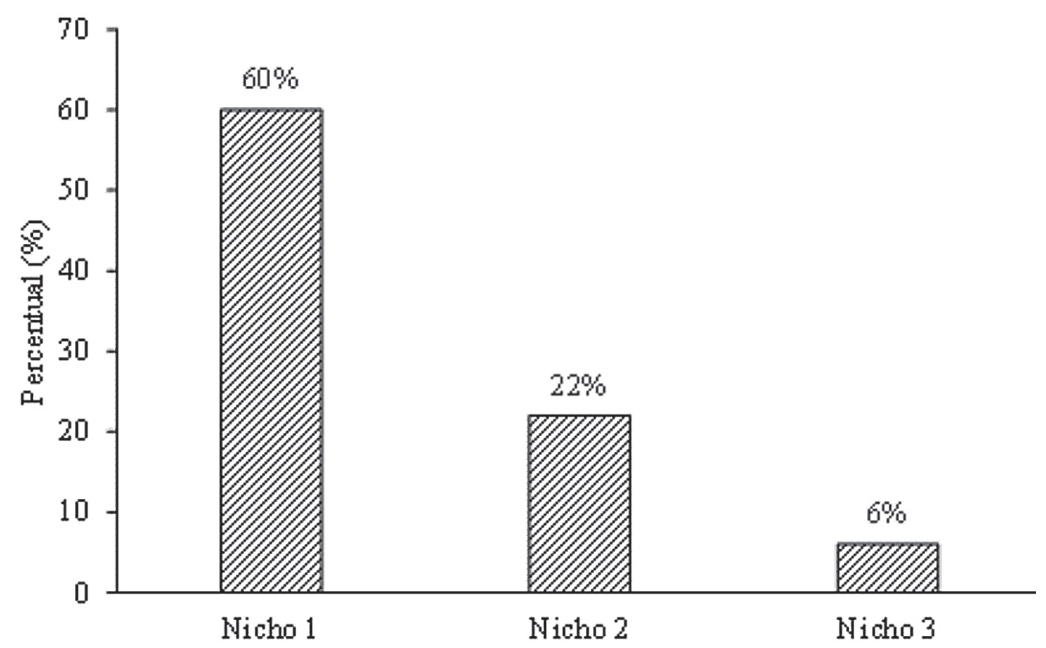

Figura 2 - Nichos de consumidores que consomem leite UHT todos os dias da semana 
Segundo as informações de Fonti Furnols et al. (2009) a frequência de consumo do produto é um dos principais fatores que deve ser considerado quando avaliado a aceitabilidade sensorial do produto. Dutcoksy (2013) também destaca que entre os fatores mais comuns relacionados à aceitabilidade está a frequência de consumo do alimento.

\section{Grupos de foco}

Os participantes das sessões dos grupos de foco possuíam o hábito de consumir leite UHT no mínimo quatro vezes na semana, a maioria era do sexo feminino $(88,9 \%)$ e tinham idade entre 18 e 33 anos (72,3\%). Em relação ao grau de instrução: $50 \%$ possuíam curso técnico incompleto, $38,9 \%$ tinham pósgraduação e $11,1 \%$ possuíam curso superior completo. $\mathrm{Na}$ aplicação da técnica de grupo de foco é importante que os participantes possuam características semelhantes, evitando assim interações e conflitos em assuntos paralelos (MALHOTRA, 2011).

De acordo com as respostas obtidas nas sessões dos grupos de foco, verificou-se que $61,1 \%$ dos participantes observam as embalagens e os rótulos do leite no momento da compra, já 38,9\% argumentaram que são consumidores fiéis a determinada marca, e por isso não consideram importante aspectos da embalagem e rotulagem do produto. Porém, mesmo os participantes que observam a embalagem e rotulagem no momento da compra, também destacaram a marca como um fator importante no processo de escolha e compra do leite, além de considerarem importantes outros fatores, como preço, praticidade da embalagem e validade do produto. Aspectos estes também verificados no estudo de Gomes et al. (2012), os quais avaliaram a influência da embalagem de leite no comportamento do consumidor.

Segundo Bendino et al. (2012), os consumidores de alimentos não demonstram interesse pelas informações contidas nos rótulos, pois desconhecem os benefícios que elas trazem. Assim, conforme este autor, ações educativas deveriam ser criadas para orientar a população sobre a importância da leitura dos rótulos de alimentos e suas informações nutricionais e assim tornar o consumidor mais consciente no momento da aquisição dos alimentos.

Considerando as seis embalagens utilizadas neste estudo, foi possível observar que $66,7 \%$ dos participantes preferem embalagem com fundo branco, rotulagem colorida e figuras relacionadas ao processo produtivo do leite, corroborando o estudo realizado por Milagres et al. (2014), os quais verificaram que embalagens coloridas, com formatos modernos, e que se diferenciam das demais na prateleira são fatores que os consumidores consideram na compra do produto. Os participantes destacaram ainda que a rotulagem não deve ser poluída e todas as informações contidas na embalagem devem apresentar um tamanho de letra que favoreça sua leitura, além disso destacaram que a cor vermelha das imagens não seria a mais apropriada para embalagem de leite, preferindo as cores azul, verde ou rosa.

Outro aspecto destacado pelos participantes, quando apresentado as embalagens de leite, foi a praticidade da abertura das embalagens. $72,2 \%$ dos participantes destacaram como ponto positivo a abertura "tipo rosca" e como ponto negativo as embalagens que necessitam de objeto cortante para sua abertura, além disto, estas embalagens não apresentam dispositivo de fechamento após sua abertura. Gomes et al., (2012) verificaram em seu estudo, que os consumidores preferem embalagens de leite com sistema de fechamento seguro (tampa rosqueável), que trazem conforto e praticidade.

Considerando as diferentes embalagens analisadas neste estudo, foi possível verificar que a embalagem de multicamada, contendo polietileno, foi destacada pelos participantes do grupo de foco, como a menos prática em 
relação ao sistema de abertura, pois exige objetos cortantes, e não apresenta sistema de abertura e fechamento, além disso, precisa ser colocada num contentor para ser manuseada e acondicionada no refrigerador após sua abertura.

Em relação as informações nutricionais e a especificação dos ingredientes contidos nas embalagens de leite, os participantes dos grupos de foco destacaram que são informações importantes e que deveriam ser consideradas no momento da compra, porém apenas $16,7 \%$ realmente observam estas informações quando adquirem o leite no supermercado. A porcentagem de consumidores que observam informações na embalagem do presente estudo é inferior quando comparado ao estudo realizado por Milagres et al., (2014), os quais concluíram que 56\% dos participantes observaram as informações referente aos ingredientes presentes na rotulagem do produto e $78 \%$ disseram escolher o produto que possui ingredientes adicionais que tem o propósito de melhorar a qualidade nutricional do produto.

O pouco interesse na observação das informações nutricionais e a especificação dos ingredientes pode ser atribuído ao fato de a maioria dos membros do grupo de foco possuírem apenas o curso técnico incompleto. Conforme Siqueira et al (2014), quanto maior o grau de escolaridade, maior o hábito de leitura dos rótulos em relação as informações nutricionais e ao tipo e quantidade de ingrediente.

No que se refere aos selos de certificação de qualidade inseridos na rotulagem do produto, verificou-se que $72,2 \%$ dos participantes não observam a existência destas certificações no momento da compra do leite. Este resultado mostra a pouca importância que o consumidor atribui a produtos com diferencial de qualidade. Conforme Pontes et al. (2009), os selos de certificação conferem mais credibilidade aos alimentos e também aos fabricantes, além de proporcionar mais segurança ao consumidor em relação aos benefícios dos produtos certificados.

Neste estudo, também foi possível verificar que $77,8 \%$ dos participantes dos grupos de foco não mudaram seus hábitos de consumo em relação a marca do leite, após noticiários referente as fraudes e adulterações deste produto. Inclusive marcas de leite que foram divulgadas no envolvimento de fraudes continuaram a ser consumidas pelos participantes, o que evidencia a falta de conhecimento dos consumidores em relação às substâncias que são utilizadas para fraudar ou adulterar o leite. Conforme Cortez et al. (2010) estas fraudes podem resultar na diminuição do valor nutricional, alteração da qualidade dos produtos beneficiados e podem aumentar o risco de doenças em virtude da presença de determinadas substâncias não permitidas.

Além disso, vários participantes do grupo de foco destacaram que são pouco exigentes com a qualidade sensorial do leite que consomem e para decisão de compra do produto consideram as características não sensoriais, como por exemplo a marca, a embalagem, o rótulo e o preço. A pouca exigência dos consumidores na qualidade sensorial do leite, pode ser corroborado com o estudo desenvolvido por Cortez et al., (2010), os quais realizaram a avaliação sensorial de amostras de leite fraudadas com água, soro de queijo, soro fisiológico e soro glicosado e verificaram que os provadores detectaram a adição de água no leite, apenas em amostras contendo 30\%. Nos testes com adição de soro de queijo, os julgadores perceberam a adulteração apenas em amostras contendo $45 \%$ de soro. Para os tratamentos com $10 \%, 20 \%$ e $30 \%$ de soro fisiológico e soro glicosado, os julgadores foram capazes de identificar a adição aos níveis de $20 \%$ e $30 \%$, respectivamente.

No presente estudo, ainda foi possível verificar que alguns consumidores não estão atentos aos problemas de qualidade 
e segurança dos alimentos, pois $33,3 \%$ dos participantes dos grupos de foco não souberam identificar nenhuma marca de leite que havia sido divulgada, através da Operação Leite Compensado, com problemas de fraude e adulterações. No entanto, cabe destacar que das seis marcas apresentadas aos participantes nas sessões de grupo, três (50\%) já haviam sido identificadas com problemas de qualidade.

Neste contexto, verifica-se que apesar das pessoas terem se tornado mais exigentes em relação à qualidade do leite, ainda é preciso modificar os hábitos destes consumidores, principalmente, no que se refere à segurança dos alimentos. Também é importante que os consumidores selecionem com maior rigor os alimentos adquiridos no comércio e cobrem do poder público melhorias sanitárias. Dessa forma, faz-se necessária uma melhor atuação dos órgãos fiscalizadores em todos os níveis de produção, intensificando as ações junto aos produtores, transportadores e indústrias processadoras de leite.

\section{CONCLUSÕES}

Mediante os resultados obtidos, foi possível concluir que na compra do leite, os consumidores priorizam as informações contidas nos rótulos e o formato das embalagens e não a qualidade do produto. Alguns consumidores desconhecem os riscos que as adulterações realizadas no leite podem ocasionar, pois a maioria dos participantes da técnica de grupo de foco não mudou seus hábitos em relação ao consumo de determinadas marcas de leite, mesmo após relatos de fraudes do produto apresentado.

Portanto, é de fundamental importância a intensificação da fiscalização junto aos produtores, transportadores e laticínios. Além de maiores investimentos pelo governo, em tecnologias para desta forma, melhorar o sistema de detecção de fraudes, visando proteger a saúde dos consumidores.

\section{REFERÊNCIAS BIBLIOGRÁFICAS}

ASSOCIAÇÃO BRASILEIRA DA INDÚSTRIA DE LEITE LONGA VIDA (ABLV), Brasil: Mercado Total de Leite Fluido, Estatísticas. Disponível em: <http://www.ablv.org.br/ Estatisticas.aspx>. Acesso em: 09 mar. 2015.

BENDINO, N. I. et al. Avaliação do conhecimento e dificuldades de consumidores fre quentadores de supermercado convencional em relação à rotulagem de alimentos e informação nutricional. Journal Health Sciences Institute, v. 30, n. 3, p. 261-265, 2012.

BRASIL, Ministério de Agricultura, Pecuária e Abastecimento. Nova Legislação de Produtos Lácteos: Revisada, ampliada e Comentada, $3^{\text {a }}$ Edição, São Paulo: Fonte, 2011. 616 p.

CHAE, J. E. et al. Same-different discrimination for assessing consumer discriminability between milks with subtle differences, Food Quality and Preference, v. 21, n. 4, p. 427-438, 2010.

CORTEZ, M. A. S. et al. Características físico-químicas e análise sensorial do leite pasteurizado adicionado de água, soro de queijo, soro fisiológico e soro glicosado. Revista do Instituto de Laticínios Cândido Tostes, v. 376, n. 65, p. $18-25,2010$.

MINIM, V. P. R. Grupo de foco. In: DELLA LUCIA, S. M.; MINIM, V. P. R. Análise sensorial: estudos com consumidores. Viçosa: UFV, 2006. p. 85-109.

DRAKE, M. A. et al. Relating sensory and instrumental analyses. In: JOHNSON, S. Sensory-Directed Flavor Analysis. Boca Raton: Ray Marsili, 2006. p. 23-55.

DUTCOKSY, S. D. Análise Sensorial de Alimentos. $4^{\text {a }}$ Ed. Curitiba: Pucpress, Curitiba, 2013. 531p.

FONT I FURNOLS, M. F. et al. Acceptability 
of lamb fed on pasture, concentrate or combinations of both systems by European consumers. MeatScience, v. 81, n. 1, p. 196202, 2009.

KLEEF, E. V. et al. Consumer research in the early stages of new product development: a critical review of methods and techniques. Food Quality and Preference, v. 16, n. 3, p. 181-201, 2005.

GOMES, L. M. C. et al. Leite: Influencia da embalagem no comportamento do consumidor. Revista do Instituto de Laticínios Cândido Tostes, v. 67, n. 384 p. 71-75, 2012.

\section{MAlHOtRA, N. Pesquisa de Marketing. $3^{\text {a }}$} ed. São Paulo: Pearson Prentice Hall, 2011.

MCSWEENEY, P. L. H.; FOX, P. F. Advanced Dairy Chemistry. $3^{\text {a }}$ ed. v. 3, Lactose, water, salts and minor constituents. Heidelberg: Springer; 2009. 778p.

MILAGRES, M. P. et al. Fatores da Embalagem de Leite com Concentração Aumentada de Melatonina na Intenção de Compra do Consumidor. Revista do Instituto de Laticínios Cândido Tostes, v. 01, n. 69, p. 25-36, 2014.

MEILGAARD, M. et al. Sensory Evaluation Techniques. 4th ed. Boca Raton: CRC Press, 464p. 2007.

NÖRNBERG, M. F. B. L. et al. Bactérias psicrotróficas e atividade proteolitíca no leite cru refrigerado. Acta Scientiae Veterinariae, v. 37, n. 2, p. 57-63, 2009.

OZER, B.; AKDEMIR-EVRENDILEK, G. Dairy Microbiology and Biochemistry: Recent Developments, Ed. CRC Press, 2014. 464p.

PONTES, T. E. et al. Orientação Nutricional de crianças e adolescentes e os novos padrões de consumo: propagandas, embalagens e rótulos.
Revista Paulista de Pediatria, v. 27, n. 1, p. 99-105, 2009.

QUEIROZ, M. I.; TREPTOW, R. O. Análise Sensorial para Avaliação da Qualidade dos Alimentos. Editora da FURG, Rio Grande, 2006. 266p.

SIQUEIRA, R. S. S. et al Avaliação do entendimento e da atitude do consumidor diante das informações veiculadas na rotulagem de produtos alimentícios na Grande Vitória, Espírito Santo. Nutrire. v. 39, n. 2, p. 214-221, 2014.

STONE, H. S.; SIDEL, J. L. Sensory evaluation practices. San Diego: Academic Press, 1993. 308p

STONE, H.; SIDEL, J. L. Sensory evaluation practices. 3rd.ed. London: Academic Press, 2004. 408 p.

TRONCO, V. M. Manual para Inspeção da Qualidade do Leite. 5a Edição, Editora da UFSM, p. 95-127, 2013.

VIDAL-MARTINS, A. M. et al. Evolução do índice proteolítico e do comportamento reológico durante a vida de prateleira de leite UAT/ UHT. Ciência e Tecnologia de Alimentos, v. 25, n. 4, p. 698-704, 2005.

VILLANUEVA, N. D. M. et al. Performance of the hybrid hedonic scale as compared to the tradicional hedonic, self-adjusting and ranking scales. Food Quality and Preference, v. 16, n. 8, p. 691-703, 2005 .

YATES, M. D., DRAKE, M. A. Texture properties of Gouda cheese. Journal of Sensory Studies, v. 22, n. 5, p. 493 -503, 2007.

ZENI, M. P. et al. Influência dos microrganismos psicrotróficos sobre a qualidade do leite refrigerado para produção de UHT. Unoesc \& Ciência-ACET, v. 4 n. 1, p. 61-70, 2013. 